\title{
COMMENTARY
}

\section{Adequate thromboprophylaxis in critically ill patients}

\author{
Marcel Levi* \\ See related research by Robinson et al., http://ccforum.com/content/14/2/R41
}

\begin{abstract}
Venous thromboembolism is a relatively frequently occurring complication in critically ill patients admitted to the ICU despite prophylactic treatment with subcutaneous low molecular weight heparin. Several studies show that critically ill patients have significantly lower plasma anti-factor-Xa activity levels compared to control patients after administration of subcutaneous heparin. Robinson and colleagues show in this issue of Critical Care dose-dependent but relatively low levels of anti-factor Xa activity at increasing doses of enoxaparin. Anti-factor Xa levels thought to be required for adequate thromboprophylaxis are observed only at doses of enoxaparin that are one and a half times higher than the conventional dose $(40 \mathrm{mg})$.
\end{abstract}

In this issue of Critical Care, Robinson and colleagues [1] investigate the effect of increasing doses of the low molecular weight (LMW) heparin enoxaparin (commonly used as prophylaxis against venous thromboembolism (VTE)) on systemic heparin concentrations, expressed as anti-factor Xa levels. VTE is a common complication in critically ill patients. Reported rates for deep venous thrombosis in patients admitted to the ICU range from 22 to $80 \%$ depending on patient characteristics. Thromboprophylaxis with unfractionated or LMW heparin lowers the risk for deep venous thrombosis by more than 50\% [2]. Nevertheless, the risk of VTE in critically ill patients receiving LMW heparin prophylaxis is still much higher than in other patient groups. Amongst several factors that may explain the higher incidence of VTE in critically ill patients, such as full immobilisation or withholding anticoagulant prophylaxis because of a high bleeding risk, it was hypothesized that

*Correspondence: m.m.levi@amc.uva.nl

Department of Vascular Medicine and Internal Medicine, Academic Medical Center, University of Amsterdam, Meibergdreef 9, 1105 AZ Amsterdam, The Netherlands limited bioavailability (that is, lower plasma anti-factor Xa activity) of subcutaneously administered heparin in those patients with impaired peripheral circulation, due to vasopressor medication to maintain central blood pressure, might be important. Indeed, in a first comparative trial it was shown that critically ill patients on high dose vasopressor medication had much lower anti-factor Xa concentrations after the subcutaneous administration of LMW heparin in comparison with intensive care patients that had lower doses of vasopressor or in comparison with patients in the surgical ward [3]. A subsequent study also found consistently lower anti-factor Xa levels after subcutaneous heparin in critically ill patients [4]. In another similar study, critically ill patients with excessive subcutaneous oedema had lower anti-factor $\mathrm{Xa}$ concentrations compared to a control group without oedema [5]. This observation was confirmed in a group of critically ill multiple trauma patients, who showed variable and low heparin concentrations after subcutaneous injections [6].

Robinson and colleagues [1] compared plasma antifactor Xa levels after the subcutaneous administration of the LMW heparin enoxaparin at the conventional dose (40 mg) and at increasingly higher doses (up to $70 \mathrm{mg}$ ) in intensive care patients. They found a dose-dependent increase in peak anti-factor Xa levels (4 hours after the injection) ranging from $0.13 \mathrm{IU} / \mathrm{ml}$ at the conventional $40 \mathrm{mg}$ dose to $0.29 \mathrm{IU} / \mathrm{ml}$ at the $70 \mathrm{mg}$ dose. Considering that optimal efficacy and safety of LMW heparin for thromboprophylaxis in orthopaedic and abdominal surgery was achieved with dosages of heparin resulting in peak plasma anti-factor Xa activities ranging between 0.25 and $0.30 \mathrm{IU} / \mathrm{ml}$ [7], it may be concluded that critically ill patients need much higher doses of LMW heparin than other patients. Based on the findings of Robinson and colleagues, the subcutaneous dose of LMW heparin should be increased to $60 \mathrm{mg}$ daily. Alternatively, direct intravenous administration of (LMW) heparin may be considered; however, experience with this type of thromboprophylaxis is limited.

The mechanism by which critically ill patients have lower anti-factor Xa levels after subcutaneous administration of heparin is not completely understood. The 
initial hypothesis was that patients on high dose vasopressor medication had impaired subcutaneous blood flow and thereby limited ability to adsorb the subcutaneous heparin [3]. An alternative explanation is that the presence of oedema hinders the absorption of heparin, although that hypothesis was not proven [5]. In addition, it has been suggested that systemic inflammation and associated multiple organ dysfunction may have an impact on heparin binding to plasma proteins and drug metabolism [8].

The clinical relevance of lower anti-factor Xa levels after conventional doses of (LMW) heparin in critically ill patients is also not totally clear. Theoretically, the low anti-factor Xa levels may lead to suboptimal prophylaxis and could indeed be a contributory factor to the higher incidence of thromboembolic complications in critically ill patients despite routine thromboprophylaxis. However, this has never been demonstrated in a clinical study. Based on the observations of Robinson and colleagues and others, a randomized controlled trial with conventional versus higher doses of thrombosis prophylaxis in critically ill patients aiming at the reduction of the incidence of VTE and other clinically relevant outcomes is justified. Such a study would also enable the evaluation of bleeding complications related to the administration of prophylactic heparin, as intensive care patients are at higher risk for hemorrhage as well $[9,10]$.

In summary, there is ample evidence that conventional thromboprophylaxis leads to lower systemic heparin levels in critically ill patients. It is not clear whether this contributes to the relatively high incidence of VTE in intensive care patients. A clinical trial evaluating higher doses of heparin for prevention of VTE and assessing the bleeding risk of such an approach is justified.

Abbreviations

$\mathrm{LMW}=$ low molecular weight; VTE = venous thromboembolism.
Competing interests

The author declares that he has no competing interests.

Published: 21 April 2010

References

1. Robinson S, Zincuk A, Strøm T, Larsen TB, Rasmussen B, Toft P: Enoxaparin, effective dosage for intensive care patients: double-blinded, randomised clinical trial. Crit Care 2010, 14:R41.

2. Cook DJ, Crowther MA: Thromboprophylaxis in the intensive care unit: focus on medical-surgical patients. Crit Care Med 2010, 38:S76-S82.

3. Dörffler-Melly J, de Jonge E, Pont AC, Meijers J, Vroom MB, Büller HR, Levi M: Bioavailability of subcutaneous low-molecular-weight heparin to patients on vasopressors. Lancet 2002, 359:849-850.

4. Priglinger U, Delle Karth G, Geppert A, Joukhadar C, Graf S, Berger R, Hülsmann M, Spitzauer S, Pabinger I, Heinz G: Prophylactic anticoagulation with enoxaparin: Is the subcutaneous route appropriate in the critically ill? Crit Care Med 2003, 31:1405-1409.

5. Rommers MK, Van der Laan N, Egberts TC, van den Bemt PM: Anti-Xa activity after subcutaneous administration of dalteparin in ICU patients with and without subcutaneous oedema: a pilot study. Crit Care 2006, 10:R93.

6. Haas CE, Nelsen JL, Raghavendran K, Mihalko W, Beres J, Ma Q, Forrest A: Pharmacokinetics and pharmacodynamics of enoxaparin in multiple trauma patients. J Trauma 2005, 59:1336-1343; discussion 1343-1344.

7. Leyvraz PF, Bachmann F, Hoek J, Büller HR, Postel M, Samama M, Vandenbroek MD: Prevention of deep vein thrombosis after hip replacement: randomised comparison between unfractionated heparin and low molecular weight heparin. BMJ 1991, 303:543-548.

8. Mayr AJ, Dünser M, Jochberger S, Fries D, Klingler A, Joannidis M, Hasibeder W, Schobersberger W: Antifactor Xa activity in intensive care patients receiving thromboembolic prophylaxis with standard doses of enoxaparin. Thromb Res 2002, 105:201-204.

9. Levi MM, Eerenberg E, Lowenberg E, Kamphuisen PW: Bleeding in patients using new anticoagulants or antiplatelet agents: risk factors and management. Neth J Med 2010, 68:68-76.

10. Cook D, Douketis J, Meade M, Guyatt G, Zytaruk N, Granton J, Skrobik Y, Albert M, Fowler R, Hebert P, Pagliarello G, Friedrich J, Freitag A, Karachi T, Rabbat C, Heels-Ansdell D, Geerts W, Crowther M; Canadian Critical Care Trials Group: Venous thromboembolism and bleeding in critically ill patients with severe renal insufficiency receiving dalteparin thromboprophylaxis: prevalence, incidence and risk factors. Crit Care 2008, 12:R32.

doi:10.1186/cc8949

Cite this article as: Levi M: Adequate thromboprophylaxis in critically ill patients. Critical Care 2010, 14:142. 